\title{
THE EFFECTS OF CORS NETWORK GEOMETRY AND DIFFERENTIAL NRTK CORRECTIONS ON GNSS SOLUTIONS
}

\author{
Gino DARDANELLI ${ }^{1}$ (D), Claudia PIPITONE ${ }^{1}$ (D)
}

DOI: 10.21163/GT_2021.163.05

\begin{abstract}
:
The widespread availability of Continuosly Operating Reference Station (CORS) all over the world, allows to improve more scientific and technical studies on the use of satellite positioning techniques. The aim of this paper is to understand the effects of a GNSS CORS network geometry and differential corrections on the solutions. The analysis is carried out using ten different network configurations, with different inter-distances between the stations within GNSMART Geo++ software. The coordinates of one control point placed on the top of the Department of Engineering (University of Palermo, Italy) have been used to perform several static positioning mode test within fourthy hours. Different surveys have been performed, including four separate session tests, with acquisitions of one hour each. The analysis has been carried out using the traditional network solutions, such as the Virtual Reference Station (VRS), the Flächen Korrektur Parameter (FKP) and other two more recent techniques, which use the satellite corrections from the nearest (Near) and the farest (Far) stations. Results confirmed the great reliability of the GNSS network, with centimetre precision in terms of coordinates (North, East and Ellipsoidal Height), whether changing the geometric configuration of the network or the corrections.
\end{abstract}

Key-words: GNSS, CORS, Network configuration, NRTK, VRS, FKP, Geo++.

\section{INTRODUCTION}

In the last few decades, the high performances of the real-time satellite positioning allowed the increasing of the number of the Network Real Time Kinematic (NRTK)-GNSS stations worldwide. Indeed, the use of GNSS networks allows reducing the problems occurred with the RTK approach, mainly connected to the distance between the master and rover receivers. Indeed, the latter needs to be less than 20 kilometers, for the ambiguity-phase resolution using the "on-the-fly" mode to obtain the centimeter level of precision (Zhang and Teunissen, 2011).

Recently, several studies have been performed by Universities, Research Center, Public or Private Institutions, to test the precision and the reliability of NRTK-GNSS positioning, focusing on the repeatability of the experiments. The Department of Geomatics, University of Calgary (Canada), performed one of the earliest experiments. The MultiRef approach has been tested to analyze the influence of the network geometry configuration on the achievable precision. The analysis demonstrated that best results can be achieved when the reference stations are distributed at the same distance along the configuration scheme; also, the CORS outside the analysed network do not increase the precision achievable anyway (Fortes et al., 2003, Pugliano and Lachapelle, 2005).

At the Ohio State University (USA), the analyses developed by Grejner-Brzezinska provided a great contribution to the research. The effects of the network geometric configuration and the reliability of the differential corrections, using 24 hours data, but also the horizontal and vertical achievable precision are discussed in Grejner-Brzezinska et al. in 2005. Other studies focused on the network calibration for adverse reference-rover geometry in RTK network-based (Grejner-Brzezinska et al., 2009), the high-accuracy Differential Global Position System (DGPS) and precise point

\footnotetext{
1 Department of Engineering, University of Palermo, 90128 Palermo, Italy, gino.dardanelli@unipa.it; claudia.pipitone02@unipa.it
} 
positioning (PPP) based on CORS networks (Wielgosz et al., 2005) and the efficiency and reliability of ambiguity resolution in network-based real-time kinematic GPS (Grejner-Brzezinska et al., 2011). Also, Rizos and Satirapod discussed in 2011 the main role of GPS/GNSS setup (as CORS Networks) by creating the Global Geodetic Observing System (GGOS), managed by the International Association of Geodesy (IAG). Since 2005, in Australia, the analyses were focused on the distance between the stations, ranging from 50 to 200 kilometers, within GNSS CORS networks, such as GPSnet TM. Results have shown that the use of NRTK solutions provides high performances in terms of precision, accuracy and repeatability of the final coordinates (Gordini et. al., 2006, Hope et al., 2008, Hausler and Collier, 2013). Other studies involved the analysis of the network based geometryfree models for Three Carrier Ambiguity Resolution (TCAR) and phase bias estimation with DD and ZD code and phase measurements (Feng and Rizos, 2009).

In Great Britain, static and cinematic surveys have been conducted to evaluate the accuracy, the precision and the availability of NRTK commercial services, like SMARTnet. In both cases, centimeter precisions have been reached. Also, the influence of the number of visibile satellites, the Dilution of Precision (DOP) and the ambiguity-phase resolution time have been analysed (Aponte et al., 2009). The NRTK stations located on the border between Spain and Portugal but also those on the border between regions (Lombardia and Piemonte) of the same country (Italy) have been used for scientific purposes (Garrido et al., 2012, Dabove et al., 2016). Other studies also involved the use of NRTK stations for archaeological settlements (Inal et al., 2017, Fazio et al., 2019, Ebolese et al., 2019). In 2018, Pepe investigated the performance of the NTRK approach using several types of corrections (VRS, Nearest, FKP, MAC) with a low cost GNSS receiver equipped with Arduino jumper wires, power bank and a smartphone, employing the stop-and-go kinematic technique (Pepe, 2018).

Finally, in Poland, several tests have been also performed to evaluate the quality of the networkbased GNSS positioning services provided by all available CORS networks, using 20 reference points of the first-order geodetic network (Prochniewicz et al. 2020). The international works, already discussed, involved different methodologies and mathematical approaches to compute the network corrections. The size of the network, the number of GNSS stations and the geometric configurations have been deeply analysed in their studies. Periodically, in Australia, the improvements connected to the use of GPS-GNSS CORS networks have been analysed. As an example, in 2013, the Department of Industry, Innovation, Climate Change, Science, Research and Tertiary Education, demonstrated that the GPS-GNSS CORS network positioning allows increasing the economic benefits in terms of the Australian Gross Domestic Product (GDP). The increasing estimation of the GDP goes from \$2.3 billion and $\$ 3.7$ billion in 2012, to $\$ 7.8$ billion and $\$ 13.7$ billion in 2020 (ACIL Allen Consulting, 2013).

Focusing more deeply on this work, since 2005, the UNIPA GNSS CORS network is available in the central-western part of Sicily, Italy (Fig. 1). The design, the geodetic framework and the preliminary results of the network have been discussed in Dardanelli et al. (2020). In recent times, the UNIPA GNSS CORS network had the scientific acknowledgment through many tests in different application fields. Ammoscato et al. (2008) used data to design a GPS-GIS integrated system for electromagnetic pollution; Dardanelli et al. (2017) showed the results of technical criticalities for GIS modelling in an urban noise map; Catania et al. (2020) evaluated the positioning accuracy by comparing GNSS receivers used for mapping and guidance of agricultural machines.

Other studies referred to the use of data from UNIPA network to collect performance assessment of Precise Point Positioning (PPP) surveys using the GNSS GPS-GLONASS-Galileo Constellations. Specifically, the GNSS configurations involved were seven: GPS only, GLONASS only, Galileo only, GPS+GLONASS, GPS+Galileo, GLONASS+Galileo, and GPS+GLONASS+Galileo. The results showed significant performance improvement of the GNSS combinations compared to single GNSS constellations (Angrisano et al., 2020). Over the last couple of years, Kenyeres et al. (2019) also used data of UNIPA GNSS CORS for a European regional integration of long-term national dense network solutions, with positions and velocities for 3192 stations. Other applications involving the UNIPA GNSS CORS network have been analyzed and discussed. Dardanelli et al. (2015) and 
Dardanelli and Carella (2013) applied network corrections to trajectories calculation of MMS (Mobile Mapping System).

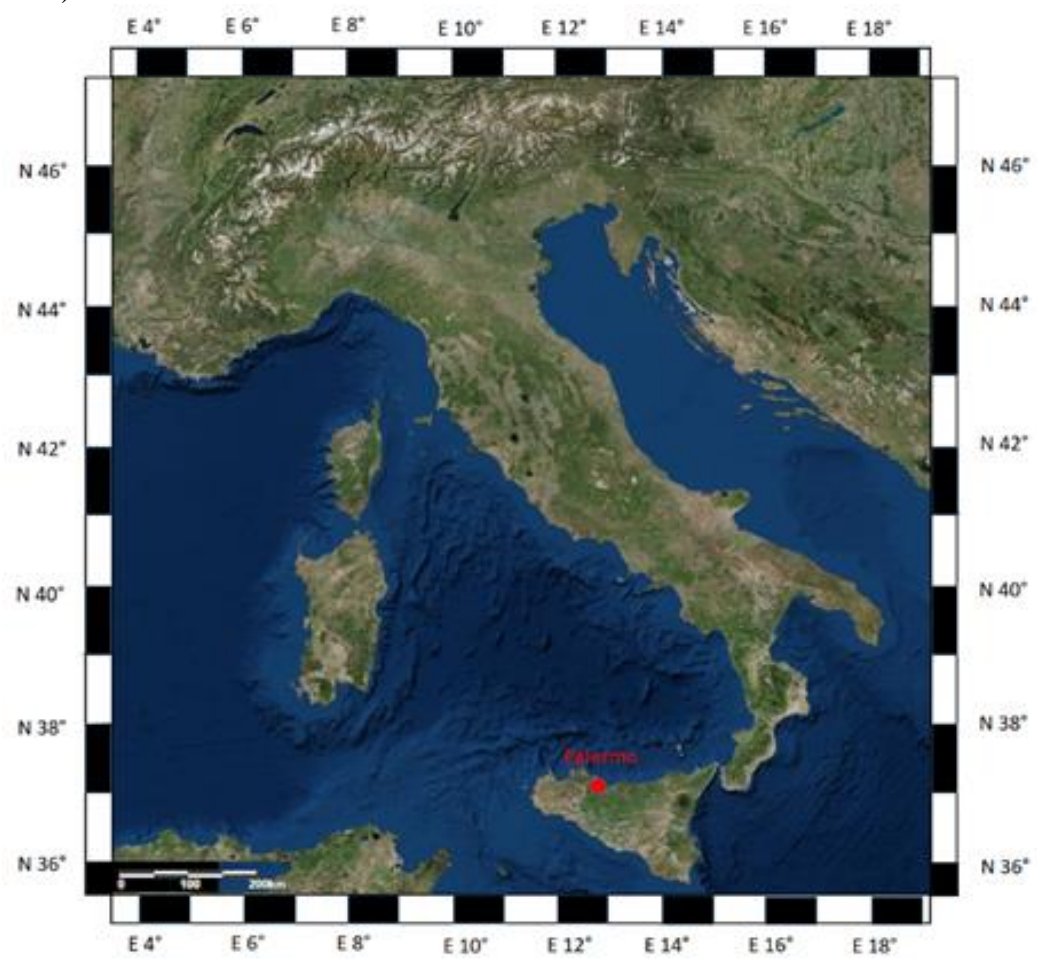

Fig. 1. Geographical position of the study area, by digital orthophoto from Italian National Geoportal, scale 1:6000000, reference system UTM-WGS8433N (ETRF2000).

Stocchi et al. (2017) used RINEX file to geodetic measurements of the stalactite elevation in geological analyses, meanwhile Dardanelli and Pipitone (2017), Dardanelli et al. (2014) and Pipitone et al. (2018) focused on dams monitoring with integrated geomatics and GNSS technique. Finally, Barreca et al. (2020) used UNIPA CORS dataset from 2008-2016 to monitor the active faulting in southwestern Sicily, with an integrated geodetic and InSAR technique.

The aim of this paper is to understand the effects of the geometric configuration and the differential corrections of a GNSS CORS network on the solutions. The analysis is carried out using ten different network configurations, with different inter-distances between the stations computed with GNSMART Geo++ software. The coordinates of one control point placed on a concrete pillar on the rooftop of the Department of Engineering have been used to perform several static positioning mode tests within fourthy hours. Different surveys have been performed, including four separate session tests, with acquisition of one hour each.

The analysis has been carried out using the traditional network solutions, such as the Virtual Reference Station (VRS) approach (Wanninger, 2003), the Flächen Korrektur Parameter (FKP) (Keenan et al. 2002, Kim et al. 2017) and other two more recent techniques, which use the satellite corrections from the nearest (Near) and the farest (Far) stations. Results confirmed the great reliability of the GNSS network, with centimetre precision in terms of coordinates (North, East and Ellipsoidal Height), whether changing the geometric configuration of the network or the corrections.

The paper is organized as follows: the description of Materials, Software used and Methods is discussed in Section 2; the Results and the Discussion of the analyses are presented in Section 3. Finally, the Conclusions and future applications are reported in Section 4. 


\section{MATERIALS, SOFTWARE USED AND METHODS}

In this work, the data set (of two months) used was collected at the Engineering Department for the geodetic survey operations carried out during the first step of network setup and consists of all available GPS/GLONASS data from UNIPA GNSS CORS, as showed in Dardanelli et al. 2020 with 8 CORS, installed on the top of a building at the: University of Palermo (PALE), Termini Imerese (TERM), Trapani (TRAP), Agrigento (AGRI), Caltanissetta (CALT), Partinico (PART), Campobello di Mazara (CAMP) and Prizzi (PRIZ) including also the external CORS of Alcamo. In table 1 list of geographical coordinates in ETRS89 of all CORS.

Table 1.

Geographical coordinates of UNIPA CORS Network in ETR89.

\begin{tabular}{|c|c|c|c|}
\hline CORS & Latitude & Longitude & UP $(\mathrm{m})$ \\
\hline AGRI & $37^{\circ} 19^{\prime} 13.00674 \mathrm{~N}$ & $13^{\circ} 36^{\prime} 04.19433 \mathrm{E}$ & 297.355 \\
\hline ALCA & $37^{\circ} 58^{\prime} 24.64002 \mathrm{~N}$ & $1^{\circ} 57^{\prime} 20.77357 \mathrm{E}$ & 354.154 \\
\hline CALT & $37^{\circ} 29^{\prime} 35.40220 \mathrm{~N}$ & $14^{\circ} 03^{\prime} 18.35414 \mathrm{E}$ & 633.969 \\
\hline CAMP & $37^{\circ} 37^{\prime} 45.32620 \mathrm{~N}$ & $12^{\circ} 44^{\prime} 41.57530 \mathrm{E}$ & 146.089 \\
\hline PALE & $38^{\circ} 06^{\prime} 19.94099 \mathrm{~N}$ & $13^{\circ} 20^{\prime} 54.42250 \mathrm{E}$ & 113.508 \\
\hline PART & $38^{\circ} 02^{\prime} 25.49135 \mathrm{~N}$ & $13^{\circ} 06^{\prime} 35.29019 \mathrm{E}$ & 247.601 \\
\hline PRIZ & $37^{\circ} 43^{\prime} 08.31149 \mathrm{~N}$ & $13^{\circ} 26^{\prime} 12.80031 \mathrm{E}$ & 961.984 \\
\hline TERM & $37^{\circ} 58^{\prime} 59.71290 \mathrm{~N}$ & $13^{\circ} 42^{\prime} 07.77880 \mathrm{E}$ & 55.31 \\
\hline TRAP & $38^{\circ} 00^{\prime} 45.43112 \mathrm{~N}$ & $12^{\circ} 32^{\prime} 28.04159 \mathrm{E}$ & 61.985 \\
\hline
\end{tabular}

The GNSS Topcon Hiper-Pro double-frequency receivers equipped with FC-100 controller and Nokia N70 mobile phone have been used for the static survey. The control point, in the ETRS89 framework, is placed on a concrete pillar on the rooftop of Palermo University, according to other studies, recently published (Angrisano et al., 2020).

The three-commercial software, used to compute the ground truth in this research, are:

- Topcon Tools ver. 8.2.3, developed by Topcon Corporation. The software allows the data processing from different devices such as total stations, digital levels and GNSS receivers, and it is used in several technical-scientific applications (Uradziński and Bakuła, 2020, Dawidowicz et al., 2015). Topcon Tools uses the Modified Hopfield Model for the tropospheric corrections. The employed positioning mode was Code-based differential ("CODE DIFF"), the time range and the cut-off angle were set to $1 \mathrm{~s}$ and 10 degrees, respectively;

- GNSMART, developed by Geo++ GNSMART was one of the earliest systems to guarantee the uniform coverage for the absolute positioning with centimeter precision in real time (Wubbena et al. 2005). The GNSS observations (GPS and GLONASS in this study) at high resolution are in RTCM 2.3 format, able to send the differential corrections (VRS, FKP, Near, Far);

-Meridiana ver. 2011, developed by Topcon Corporation, for recording data from the different corrections (VRS, FKP, Near, Far).

Preliminary, the coordinates of the control point, used to compare other measurements in real time (NRTK), have been determined with a relative static survey, obtaining high precision, and processed by Topcon Tools. The scheme involved three baselines connecting the control Point and other three CORS, specifically those of Alcamo, Prizzi, and Termini Imerese. 


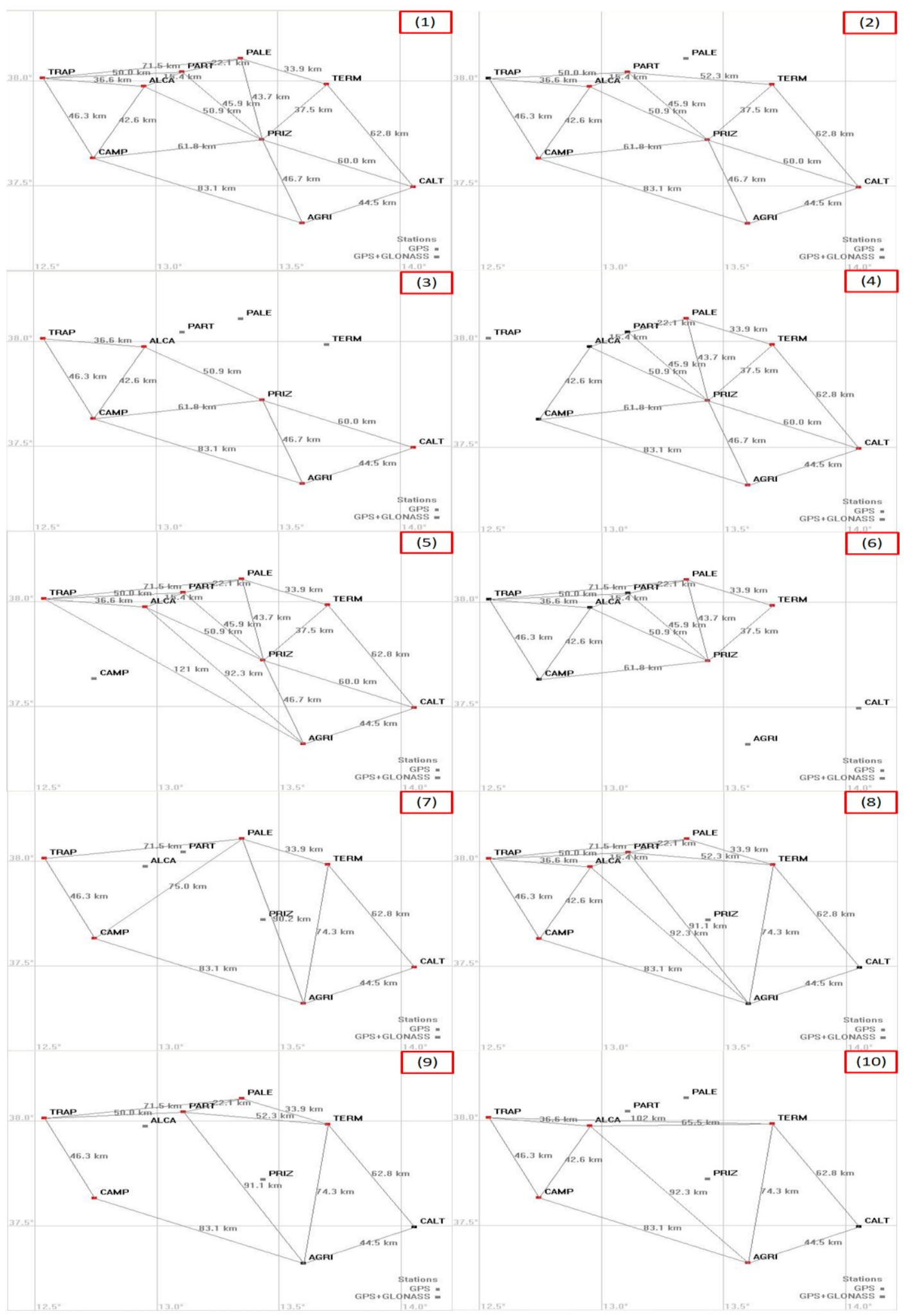

Fig. 2. GNSMART screenshot of UNIPA CORS geometry. 
Then, some CORS belonging to UNIPA network have been randomly disconnected to simulate different schemes within the GNSMART software with different inter-distances between the stations. The experiments involved many sessions, with acquisition of 40 hours without interruptions with four hours of occupation planning during the static surveys and four different connections to the stream (VRS, FKP, Near, Far) (Fig. 2).

For NRTK measurements, an experimental procedure based on different projects by Politecnico di Milano (Benciolini et al., 2006) has been performed. Specifically:

1) the measurements have been carried out during the weekdays from 8:00 am to 6:00 pm, without a preliminary check about the geometric configuration of the satellite constellations or the existence of active connected stations within the network;

2) two separate sessions, in different time over the day, have been recorded for each point aiming to obtain independent satellite configurations;

3) for each session, four independent tests (including the start up, the connection to CORS network, the ambiguity-phase fixing, the data recording, the turning off and the relight of the instruments during the tests) for each network solution are analyzed (VRS, FKP, Near, Far);

4) rate of $1 \mathrm{sec}$;

5) cut-off angle of 10 degrees;

6) the recording of the results at the fifth epoch with fixed phase solution and ambiguity phase are fixed;

7) the reject of the solution when the ambiguity phase fixing does not occur within five minutes since the connection with the software is established (float or stand-alone solution).

\section{RESULTS AND DISCUSSION}

In table 2, all results of this work are summarized, reporting for each scheme the difference between the values of the coordinates obtained from the static survey and the solutions using the differential corrections (VRS, FKP, Near, Far). The empty spaces are due to the missing differential corrections within the fixed time span in the analysis, according with experimental procedure by Politecnico di Milano (five minutes since the connection with the software is established).

Table 2.

Standard deviation of the residuals for each network solution: VRS, FKP, Near, Far (mm).

\begin{tabular}{|c|c|c|c|c|c|c|c|c|c|c|c|c|}
\hline Scheme & \multicolumn{3}{|c|}{ VRS } & \multicolumn{3}{c|}{ FKP } & \multicolumn{3}{c|}{ Near } & \multicolumn{3}{c|}{ Far } \\
\hline $\mathrm{N}$. & $\Delta \mathrm{N}$ & $\Delta \mathrm{E}$ & $\Delta \mathrm{U}$ & $\Delta \mathrm{N}$ & $\Delta \mathrm{E}$ & $\Delta \mathrm{U}$ & $\Delta \mathrm{N}$ & $\Delta \mathrm{E}$ & $\Delta \mathrm{U}$ & $\Delta \mathrm{N}$ & $\Delta \mathrm{E}$ & $\Delta \mathrm{U}$ \\
\hline 1 & 3 & 2 & 5 & 5 & 3 & 7 & 3 & 3 & 7 & 33 & 16 & 35 \\
\hline 2 & 6 & 8 & 12 & - & - & - & 5 & 4 & 17 & 119 & 54 & 48 \\
\hline 3 & - & - & - & 6 & 6 & 15 & 22 & 7 & 51 & - & - & - \\
\hline 4 & 3 & 3 & 7 & - & - & - & 3 & 3 & 6 & 29 & 21 & 33 \\
\hline 5 & 4 & 3 & 9 & 7 & 3 & 6 & 4 & 3 & 7 & - & - & - \\
\hline 6 & 5 & 4 & 7 & 5 & 6 & 14 & 4 & 3 & 6 & 13 & 10 & 50 \\
\hline 7 & 5 & 3 & 7 & 6 & 3 & 9 & 4 & 2 & 8 & 13 & 6 & 16 \\
\hline 8 & 4 & 3 & 7 & 8 & 4 & 10 & 3 & 3 & 6 & - & - & - \\
\hline 9 & 4 & 3 & 6 & 6 & 4 & 8 & 4 & 3 & 9 & - & - & - \\
\hline 10 & - & - & - & 7 & 10 & 19 & - & - & - & - & - & - \\
\hline
\end{tabular}

The results (Fig. 3-9) are discussed separately as follows:

3.1 Full network with all CORS (scheme 1);

3.2 Original full network without one CORS (schemes 2-4-5-8);

3.3 Original full network without two CORS (schemes 6-9); 
3.4 Original full network without three CORS (schemes 3-7-10);

3.5 Reference Point outside the network (schemes 2-3-10);

3.6 Reference Point within the network (schemes 1-4-5-6-7-8-9);

3.7 Original full network considering reduced inter-distances (schemes 1-2-3-4-6);

3.8 Original full network considering high inter-distance (schemes 5-7-8-9-10).

\subsection{Full network with all CORS (scheme 1)}

All CORS and all network solutions are considered in this configuration, as reported in Fig. 3 . Results show (in red) that the standard deviation of the residuals of the coordinates is $\pm 3 \mathrm{~mm}$ and \pm 2 $3 \mathrm{~mm}$ for the East and North components, respectively, while it is $\pm 5-7 \mathrm{~mm}$ for the Up component. This means that VRS, FKP and Near solutions provide similar results, in terms of standard deviation. The value for the last solution (Far), instead, is higher than the previous ones.

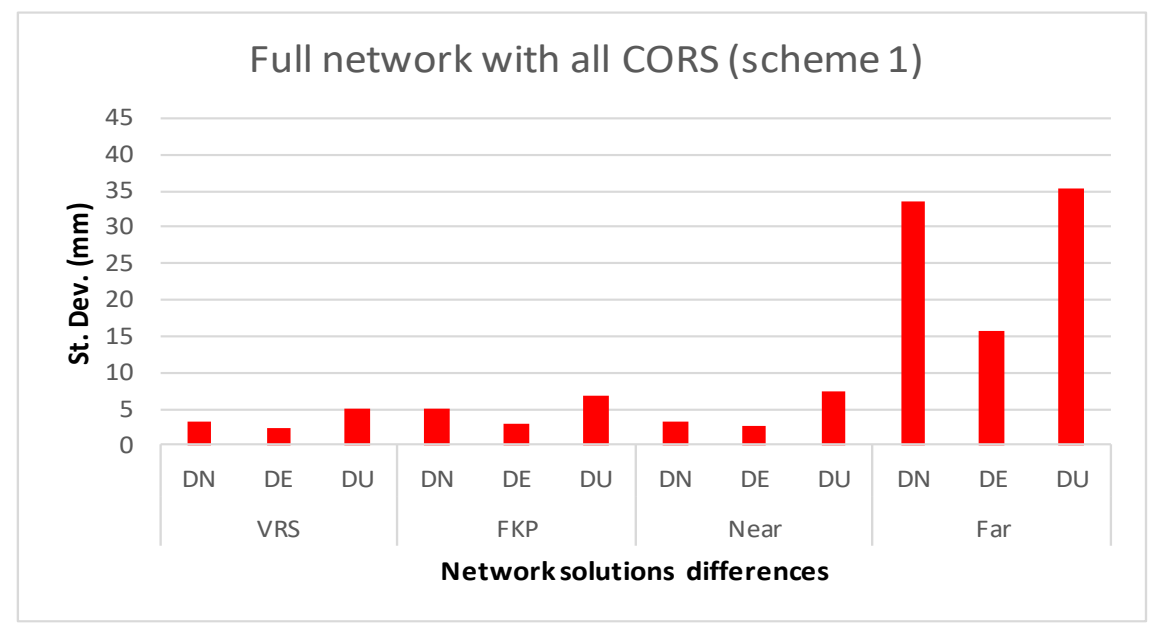

Fig. 3. Standard deviation of the residuals for each network solution: VRS, FKP, Near, Far (mm) for the full network.

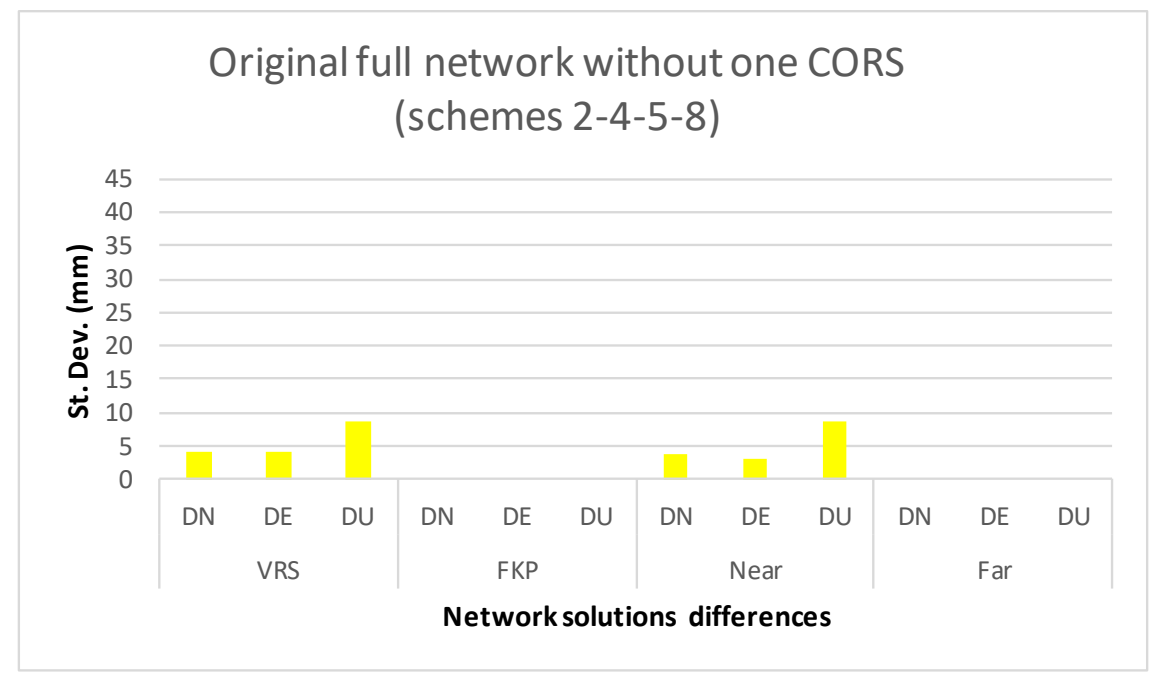

Fig. 4. Standard deviation of the residuals for each network solution: VRS, FKP, Near, Far ( $\mathrm{mm}$ ) for the original full network without one CORS. 


\subsection{Original full network without one CORS (schemes 2-4-5-8)}

In this configuration, the FKP and the Far solutions are missing for some schemes. In particular, the FKP corrections are missing in the schemes 2 and 4, but also the results of scheme 5 are not correct due to the outliers; the Far corrections are missing for schemes 5 and 8, as reported in Fig. 4.

The standard deviation for VRS and Near corrections are comparable for the two solutions (in yellow); in particular for the East and North components the values are $\pm 4 \mathrm{~mm}$ and $\pm 3-4 \mathrm{~mm}$, respectively, and for the Up component the value is $\pm 9 \mathrm{~mm}$. Obviously the results for the FKP and the Far solutions can not be discussed.

\subsection{Original full network without two CORS (schemes 6-9)}

In this configuration, in scheme 9 the Far solution was not obtained as reported in Fig. 5.

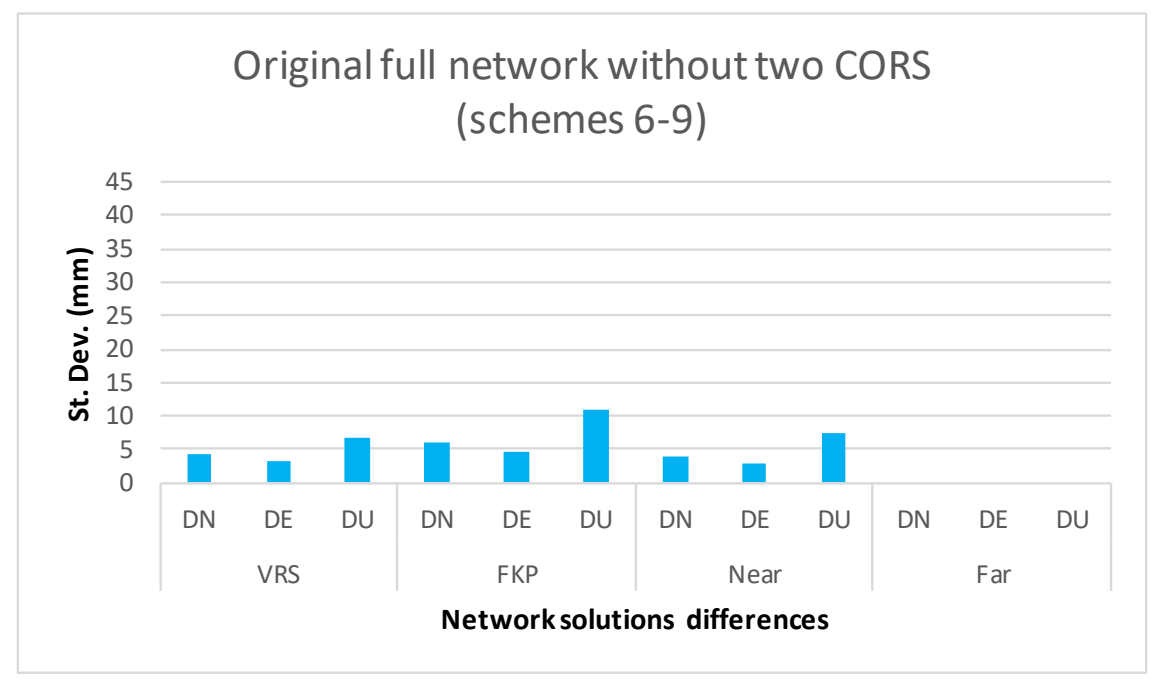

Fig. 5. Standard deviation of the residuals for each network solution:

VRS, FKP, Near, Far (mm) for the original full network without two CORS.

Results show (in light blue) that for VRS e Near solutions the average of the standard deviation is $\pm 4 \mathrm{~mm}$ and $\pm 3 \mathrm{~mm}$ for the East and North components, respectively, and $\pm 7 \mathrm{~mm}$ for the Up component, thus the two methods are comparable. The FKP correction shows higher values of standard deviation, but with the same magnitude $( \pm 6 \mathrm{~mm}$ and $\pm 5 \mathrm{~mm}$ for the East and North components, respectively and $\pm 11 \mathrm{~mm}$ for the Up component).

\subsection{Original full network without three CORS (schemes 3-7-10)}

In this configuration, the VRS and the Far solutions are missing for schemes 3 and 10. While the Near corrections are missing only for schemes 10, as reported in Fig. 6 (in black).

The limited geometric configuration influenced the results computed with GNSMART (the software needs 5 stations minimum), especially for stream corrections as VRS, Near and Far, but it 
does not affect the FKP solution for which the standard deviation is $\pm 7 \mathrm{~mm}$ and $\pm 6 \mathrm{~mm}$ for the East and North components and $\pm 14 \mathrm{~mm}$ for the Up component.

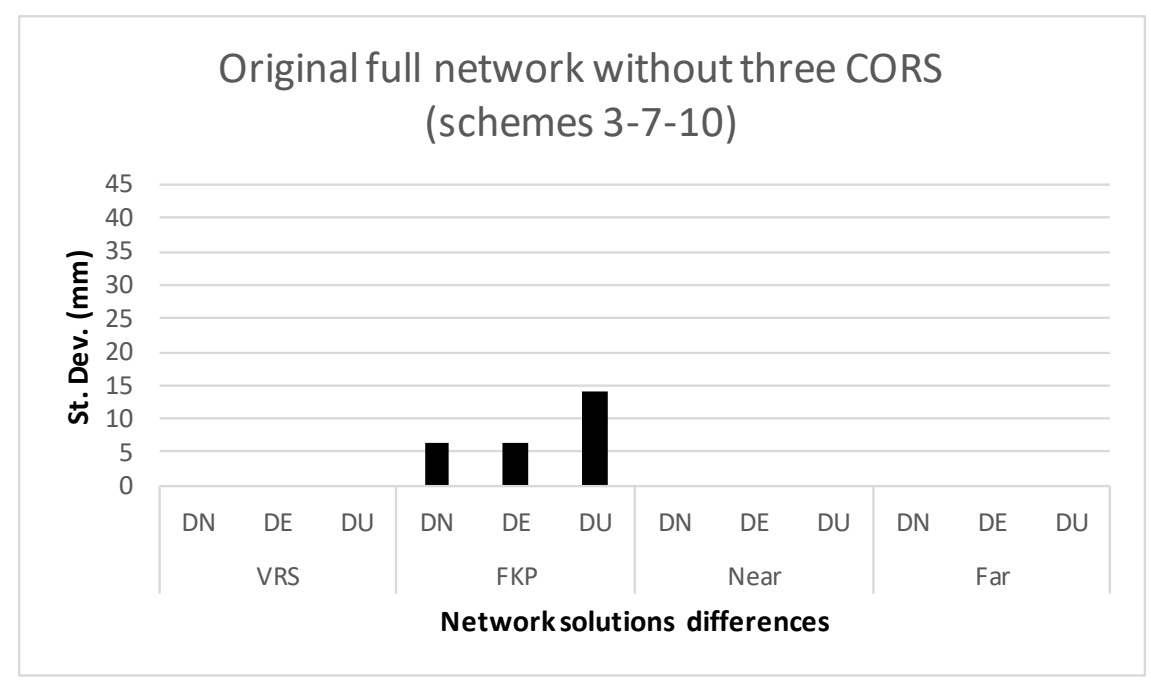

Fig. 6. Standard deviation of the residuals for each network solution: VRS, FKP, Near, Far (mm) for the original full network without three CORS.

\subsection{Reference Point outside the network (schemes 2-3-10)}

In this configuration, it is not possible computing the average of the standard deviation of the residuals, because the the corrections can not be estimated due to the impossibility to reach the minimum average value, as reported in table 3 .

Table 3.

Standard deviation of the residuals for each network solution:

VRS, FKP, Near, Far (mm) for the reference point outside the network.

\begin{tabular}{|c|c|c|c|c|c|c|c|c|c|c|c|c|}
\hline Scheme & \multicolumn{3}{|c|}{ VRS } & \multicolumn{3}{c|}{ FKP } & \multicolumn{3}{c|}{ Near } & \multicolumn{3}{c|}{ Far } \\
\hline $\mathrm{N}$. & $\Delta \mathrm{N}$ & $\Delta \mathrm{E}$ & $\Delta \mathrm{U}$ & $\Delta \mathrm{N}$ & $\Delta \mathrm{E}$ & $\Delta \mathrm{U}$ & $\Delta \mathrm{N}$ & $\Delta \mathrm{E}$ & $\Delta \mathrm{U}$ & $\Delta \mathrm{N}$ & $\Delta \mathrm{E}$ & $\Delta \mathrm{U}$ \\
\hline 2 & 6 & 8 & 12 & - & - & - & 5 & 4 & 17 & 119 & 54 & 48 \\
\hline 3 & - & - & - & 6 & 6 & 15 & 22 & 7 & 51 & - & - & - \\
\hline 10 & - & - & - & 7 & 10 & 19 & - & - & - & - & - & - \\
\hline
\end{tabular}

\subsection{Reference Point within the network (schemes 1-4-5-6-7-8-9)}

For this configuration, results are reported (in green) in Fig. 7.

According to VRS and Near solutions the values of the standard deviation are $\pm 4 \mathrm{~mm}$ and $\pm 3 \mathrm{~mm}$ 
for the East and North components, $\pm 7 \mathrm{~mm}$ for the Up component. As previously reported for scheme 1 the two methodologies are equivalent. Also, for the FKP solutions the values are $\pm 6 \mathrm{~mm}$ and $\pm 4 \mathrm{~mm}$ for the East and North components respectively and $\pm 9 \mathrm{~mm}$ for the Up component, but in this case the average of the standard deviation has been computed on six solutions instead of seven. Also, in this case the scheme 5 is affected by outliers as previously reported for other configurations.

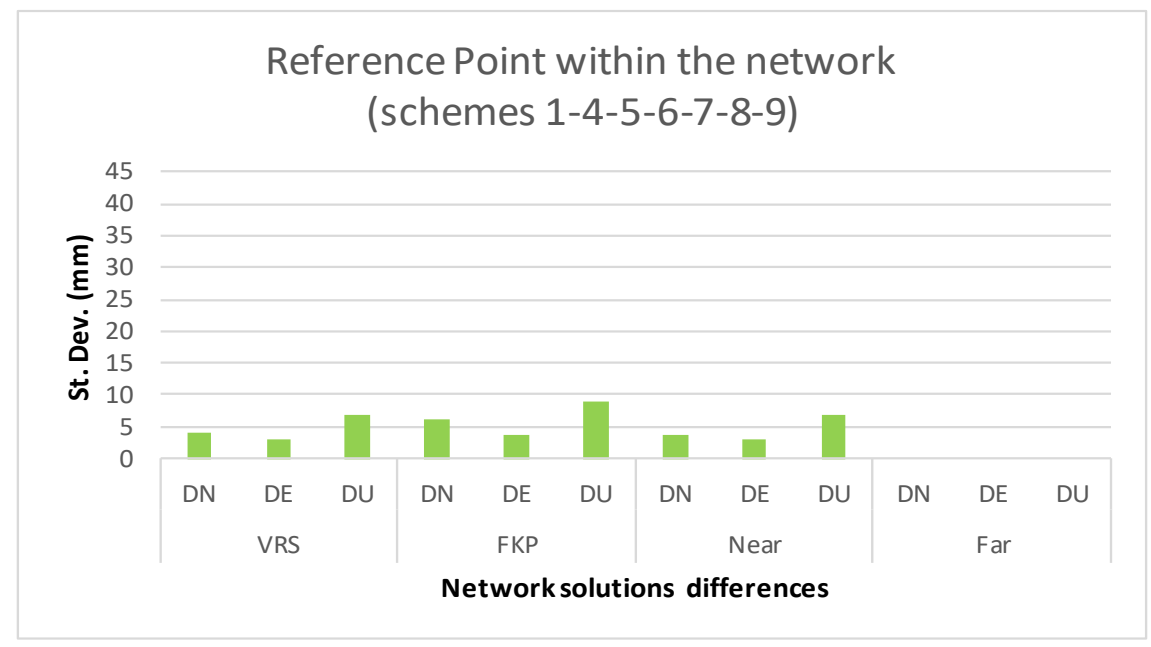

Fig. 7. Standard deviation of the residuals for each network solution:

VRS, FKP, Near, Far (mm) for the reference point within the network.

\subsection{Original full network considering reduced inter-distances (schemes 1-2-3-4-6)}

In this configuration (in orange), FKP solution are missing, meanwhile only the Near solution is completely evaluated, while the VRS and the Far corrections are computed on 4 solutions of the 5 schemes, as reported in Fig. 8.

In this configuration, referring to the Near solutions, the values of the standard deviation are \pm 7 $\mathrm{mm}$ and $\pm 4 \mathrm{~mm}$ for the East and North components, $\pm 17 \mathrm{~mm}$ for the Up component. The VRS solutions show that the standard deviation is $\pm 4 \mathrm{~mm}$ for the East and North components and $\pm 8 \mathrm{~mm}$ for the Up component; the magnitude for the Far solutions is higher, with $\pm 39 \mathrm{~mm}$ and $\pm 20 \mathrm{~mm}$ of the standard deviation for the East and North components, $\pm 33 \mathrm{~mm}$ for the Up component. Anyway, the average of the standard deviation for the VRS and Far corrections are based only on four solutions.

\subsection{Original full network considering high inter-distance (schemes 5-7-8-9-10)}

In this configuration (in purple), only the FKP solution is correctly computed (based on all solutions), while the VRS and the Near corrections are computed on 4 solutions, as reported in the following Fig. 9.

Referring to the FKP solution, the values of the standard deviation are $\pm 7 \mathrm{~mm}$ and $\pm 5 \mathrm{~mm}$ for the East and North components, respectively, and $\pm 10 \mathrm{~mm}$ for the Up component. The VRS and Near corrections, instead, show $\pm 4 \mathrm{~mm}$ and $\pm 3 \mathrm{~mm}$ of the residual of the standard deviation for or the East and North components, respectively, and $\pm 7 \mathrm{~mm}$ for the Up component. However, also in this case for both VRS and Near corrections, the average of the standard deviation is computed on 4 solutions and the scheme 5 is affected by outliers as for the other configurations. 


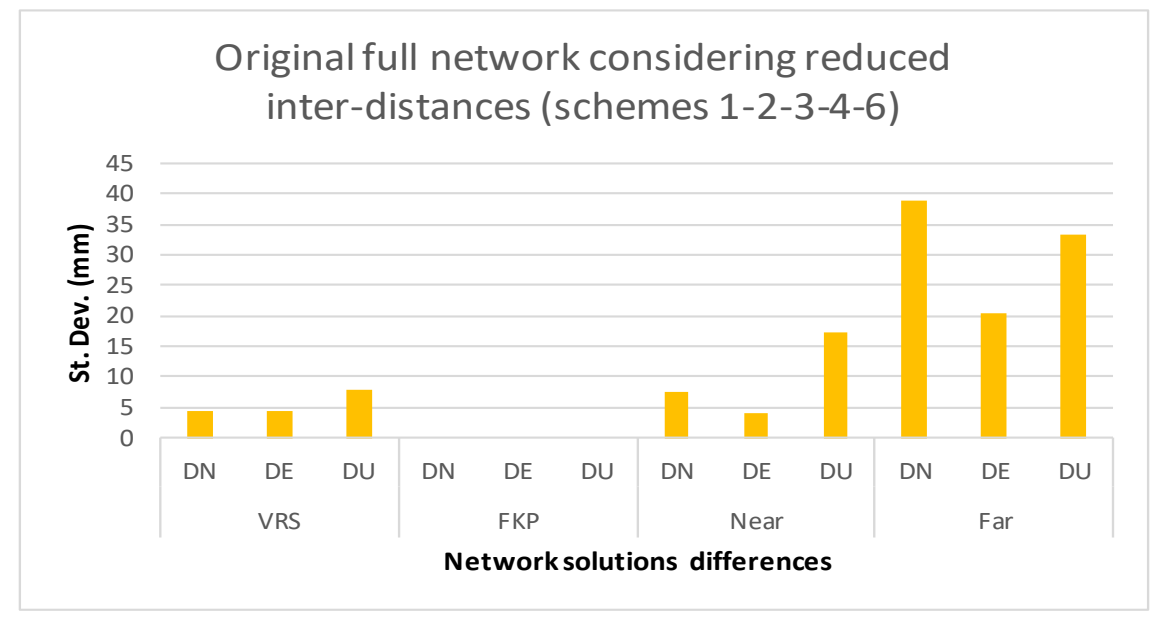

Fig. 8. Standard deviation of the residuals for each network solution:

VRS, FKP, Near, Far ( $\mathrm{mm}$ ) for reduced inter-distances within the network.

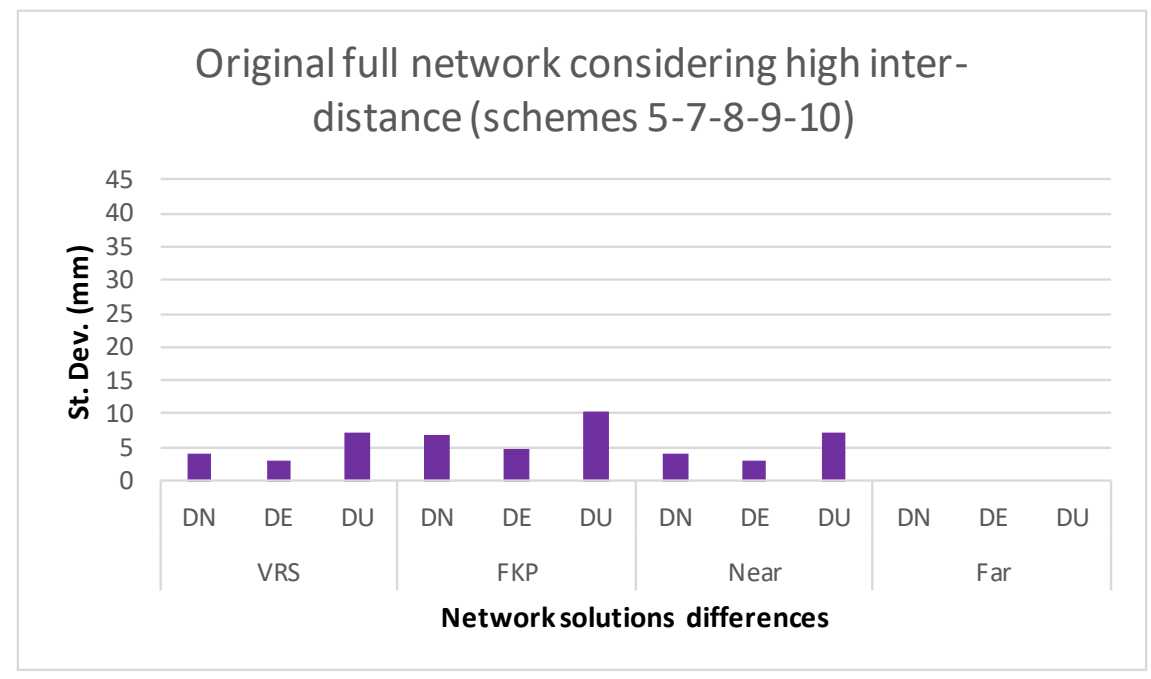

Fig. 9. Standard deviation of the residuals for each network solution:

VRS, FKP, Near, Far (mm) for high inter-distances within the network.

\section{CONCLUSIONS}

Preliminary results of this work highlighted the great performances of the differential corrections used for the purpose (VRS, FKP, Near and Far) in terms of precision and accuracy. The work is based on the combined use of NRTK and static surveys over 40 hours on a control point located on a pillar on the rooftop of Palermo University.

Specifically, using the full network with all CORS and different geometric configurations, the solutions obtained for VRS, FKP and Near corrections are equivalent, while the magnitude of the Far solution is one order higher.

Without one or two CORS, in the other configurations, the results for VRS, Near and FKP corrections are similar, especially in the configuration without two CORS; for the limited geometric 
configuration without three CORS, only the FKP solution achieves high precisions. The latter solution is also influenced by the GNSMART software that generally works with 5 stations minimum.

When the reference point is located outside the network, none of the corrections, in the configuration, reaches the minimum number to compute the average of the standard deviation; on the contrary, when the point is located within the network the solutions are similar to those found for the full network and specifically, the results for VRS and Near corrections are comparable.

Finally, in the configuration with reduced inter-distance between the CORS, best results are associated to the differential corrections, especially for the Near solution; while in the other with high inter-distance, the FKP solution shows best results.

Anyway, this works does not aim to judge the capability of the well-known GNSMART software by $\mathrm{GeO++}$, which undoubtedly is one among of the most useful GNSS processing software available, but aims to show the experimental results of this research. Future works will exploit the influence of different geometric configurations on larger networks on regional scale and the contribution of the Galileo/Beidou3 configuration on the single satellite corrections.

\section{ACKNOWLEDGMENT}

The authors would like to thank the anonymous reviewers for their constructive comments and useful suggestions.

\section{R E F E R E N C E S}

ACIL Allen Consulting. 2013. "The Value of Augmented GNSS in Australia.". Available online: http://www.acilallen.com.au/cms_files/ACIL_GNSS_positioning.pdf. [Accessed Feb. 2021].

Ammoscato, A., Corsale, R., Dardanelli, G., Scianna, A., Villa, B. (2008) "GPS-GIS integrated system for electromagnetic pollution" International Archives of the Photogrammetry, Remote Sensing and Spatial Information Sciences - ISPRS Archives, 37, 491-497.

Angrisano, A., Dardanelli, G., Innac, A., Pisciotta, A., Pipitone, C., Gaglione, S. (2020) "Performance assessment of PPP surveys with open source software using the GNSS GPS-GLONASS-Galileo constellations". Applied Sciences Switzerland, 10 (16): art. no. 5420

Aponte, J., Meng, X., Hill, C., Moore, T., Dodson, A., Burbidge, M. (2009) "Quality assessment of a networkbased RTK GPS service in the UK". Journal of Applied Geodesy, 3 (1): 25-34.

Barreca, G., Bruno, V., Dardanelli, G., Guglielmino, F., Lo Brutto, M., Mattia, M., Pipitone, C., Rossi, M. (2020) "An integrated geodetic and InSAR technique for the monitoring and detection of active faulting in southwestern Sicily". Annals of Geophysics, 63, art. no. EP03.

Benciolini, B., Biagi, L., Crespi, M., Manzino, A., Roggero, M. (2006) "Linee guida per la realizzazione di reti di stazioni permanenti di servizio". Bollettino di Geodesia e Scienze Affini, 65 (2), 90-121

Catania, P., Comparetti, A., Febo, P., Morello, G., Orlando, S., Roma, E., Vallone, M. (2020) "Positioning accuracy comparison of GNSS receivers used for mapping and guidance of agricultural machines". Agronomy, 10 (7): art. no. 924.

Dabove, P., Cina, A., Manzino, A.M. (2016) "How reliable is a Virtual RINEX?" Proceedings of the IEEE/ION Position, Location and Navigation Symposium, PLANS 2016, art. no. 7479709, 255-262.

Dardanelli, G., Carella, M. (2013) "INTEGRATED SURVEYNG WITH MOBILE MAPPING SYSTEM, EGNOS, NTRK AND LASER TECHNOLOGIES IN THE PARK "NINNI CASSARA IN PALERMO”. ISPRS Annals of the Photogrammetry, Remote Sensing and Spatial Information Sciences, 2 2W1., 95-100.

Dardanelli, G., La Loggia, G., Perfetti, N., Capodici, F., Puccio, L., Maltese, A. (2014) "Monitoring displacements of an earthen dam using GNSS and remote sensing". Proceedings of SPIE - The International Society for Optical Engineering, 9239, art. no. 923928.

Dardanelli, G., Lo Brutto, M., Pipitone, C. (2020) "GNSS cors network of the University of Palermo: Design and first analysis of data". Geographia Technica, 15 (1): 43-69.

Dardanelli, G., Marretta, R., Santamaria, A.S.; Streva, A.; Lo Brutto, M., Maltese, A. (2017) "Analysis of technical criticalities for GIS modelling an Urban noise map”. Geographia Technica, 12 (2): 41-61. 
Dardanelli, G., Paliaga, S., Allegra, M., Carella, M., Giammarresi, V. (2015) "Geomatic applications tourban park in Palermo". Geographia Technica, 10 (1): 28-43.

Dardanelli, G., Pipitone, C. (2017) "Hydraulic models and finite elements for monitoring of an earth dam, by using GNSS techniques”. Periodica Polytechnica Civil Engineering, 61 (3): 421-433.

Dawidowicz, K., Krzan, G., Świątek, K. (2015) "Relative GPS/GLONASS coordinates determination in urban areas-accuracy analysis". In 15th edition of SGEM GeoConferences, Bulgaria, Albena Resort, Vol. 2, 423430.

Ebolese, D., Lo Brutto, M., Dardanelli, G. (2019) "Uav survey for the archaeological map of lilybaeum Marsala, Italy". ISPRS Annals of the Photogrammetry, Remote Sensing and Spatial Information Sciences, 42 2/W11., 495-502.

Fazio, L., Lo Brutto, M., Dardanelli, G. (2019) "Survey and virtual reconstruction of ancient roman floors in an archaeological context". ISPRS Annals of the Photogrammetry, Remote Sensing and Spatial Information Sciences, 42 2/W11., 511-518.

Feng, Y., Rizos, C. (2009) "Network-based geometry-free three carrier ambiguity resolution and phase bias calibration". GPS Solutions, 13 (1): 43-56.

Fortes, L.P., Cannon, M.E., Lachapelle, G., Skone, S. (2003) “Optimizing a network-based RTK method for OTF positioning". GPS Solutions, 7 (2): 61-73.

Garrido, M., Giménez, E., Armenteros, J., Lacy, M.,, Gil, A. (2012) "Evaluation of NRTK positioning using the RENEP and rap networks on the southern border region of Portugal and Spain". Acta Geodaetica et Geophysica Hungarica, 47 (1): 52-65.

Gordini, C., Kealy, A.N., Grgich, P.M., Hale, M.J. (2006) “A performance analysis of sparse GNSS CORS network for real time centimetric level positioning: A case study in Victoria, Australia “. Proceedings of the Institute of Navigation - 19th International Technical Meeting of the Satellite Division, ION GNSS 2006, 2, 1196-1207.

Grejner-Brzezinska, D.A., Arslan, N., Wielgosz, P., Hong, C.-K. (2009) "Network calibration for unfavorable reference-rover geometry in network-based RTK: Ohio cors case Study". Journal of Surveying Engineering, 135-3, 90-100.

Grejner-Brzezinska, D.A., Kashani, I., Wielgosz, P. (2005) "On accuracy and reliability of instantaneous network RTK as a function of network geometry, station separation, and data processing strategy”. GPS Solutions, 9 (3): 212-225.

Grejner-Brzezinska, D.A., Kashani, I., Wielgosz, P., Smith, D.A., Spencer, P.S.J., Robertson, D.S., Mader, G.L. (2011) "Efficiency and reliability of ambiguity resolution in network-based real-time kinematic GPS CORS and OPUS for Engineers: Tools for Surveying and Mapping Applications", 133-142.

Hausler, G., Collier, P. (2013) "National Positioning Infrastructure: identifying and evaluating high accuracy GNSS service coverage across Australia”. Journal of Spatial Science, 58 (2): 191-214.

Hope, S., Gordini, C., Kealy, A. (2008) "Positional accuracy improvement: Lessons learned from regional Victoria, Australia". Survey Review, 40 (307): 29-42.

Inal, C., Kocak, O., Esen, O., Bulbul, S.; Kizgut, R. (2017) "Surveying and mapping using mobile phone in archaeological settlements". Geographia Technica, 12 (2): 82-96.

Keenan, C.R.; Zebhauser, B.E.; Euler, H.-J.; Wübbena, G. Using the Information from Reference Station Networks: A Novel Approach Conforming to RTCM V2.3 and Future V3.0;; 2002; pp. 320-327.

Kenyeres, A., Bellet, J.G., Bruyninx, C., Caporali, A., De Doncker F., Droscak, B., Duret, A., Franke, P., Georgiev, I., Bingley, R., Huisman, L., Jivall, L., Khoda, O., Kollo, K., Kurt, A.I., Lahtinen, S., Legrand, J., Magyar, B., Mesmaker, D., Morozova, K., Nágl, J., Özdemir, S., Papanikolaou, X., Parseliunas, E., Stangl, G., Ryczywolski, M., Tangen, O.B., Valdes, M., Zurutuza, J., Weber, M. (2019) "Regional integration of long-term national dense GNSS network solutions”. GPS Solutions, 23 (4): art. no. 122.

Kim, J.; Song, J.; No, H.; Han, D.; Kim, D.; Park, B.; Kee, C. (2017) Accuracy Improvement of DGPS for LowCost Single-Frequency Receiver Using Modified Flächen Korrektur Parameter Correction. ISPRS International Journal of Geo-Information, 2017, 6

Pepe, M. (2018) Cors architecture and evaluation of positioning by low-cost gnss receiver. Geodesy and Cartography, 44 (2), pp. 36-44.

Pipitone, C., Maltese, A., Dardanelli, G., Lo Brutto, M., Loggia, G.L. (2018) "Monitoring water surface and level of a reservoir using different remote sensing approaches and comparison with dam displacements evaluated via GNSS". Remote Sensing, 10 (1): art. no. 71. 
Prochniewicz, D., Szpunar, R., Kozuchowska, J., Szabo, V., Staniszewska, D., Walo, J. (2020) "Performance of Network-Based GNSS Positioning Services in Poland: A Case Study". Journal of Surveying Engineering, 146 (3): art. no. 05020006 ,

Pugliano, G., Lachapelle, G. (2005) La collocazione nel posizionamento GPS network RTK [The least-squares collocation method applied to the network RTK GPS positioning] Bollettino di Geodesia e Scienze Affini, 64 (2): 93-106.

Rizos, C., Satirapod, C. (2011) Contribution of GNSS CORS infrastructure to the mission of modern geodesy and status of GNSS CORS in Thailand. Engineering Journal, 15 (1), pp. 25-42.

Stocchi, P., Antonioli, F., Montagna, P., Pepe, F., Lo Presti, V., Caruso, A., Corradino, M., Dardanelli, G., Renda, P., Frank, N., Douville, E., Thil, F., de Boer, B., Ruggieri, R., Sciortino, R., Pierre, C. (2017) "A stalactite record of four relative sea-level highstands during the Middle Pleistocene Transition". Quaternary Science Reviews, 173, 92-100.

Uradziński, M., Bakuła, M. (2020) "Assessment of Static Positioning Accuracy Using Low-Cost Smartphone GPS Devices for Geodetic Survey Points' Determination and Monitoring". Applied Sciences Switzerland, 10, 5308.

Wielgosz, P., Grejner-Brzezinska, D., Kashani, I. (2005) "High-accuracy DGPS and precise point positioning based on Ohio CORS network Navigation", Journal of the Institute of Navigation, 52 (1): 23-28.

Wübbena, G., Schmitz, M., Bagge, A. (2005) "PPP-RTK: Precise Point Positioning using state-space representation in RTK networks". Proceedings of the 18th International Technical Meeting of the Satellite Division of The Institute of Navigation, ION GNSS 2005, 2005, 2584-2594

Wanninger, L. (2003) Virtual Reference Stations (VRS). GPS Solutions 2003, 7, 143-144

Zhang, B., Teunissen, P.J.G., Odijk, D. (2011). “A novel un-differenced PPP-RTK concept.” Journal of Navigation, 64 SUPPL. 1., S180-S191. 